\title{
ADVERSE DRUG REACTION PROFILE OF DRUGS PRESCRIBED IN CORONAVIRUS DISEASE - 19 PATIENTS - A CROSS-SECTIONAL STUDY
}

\author{
RIDHDHI K HIRAPARA ${ }^{1}$, BHARTI N KARELIA ${ }^{2 *}$, ANIL P SINGH ${ }^{1}$, ARTI TRIVEDI ${ }^{3}$
}

${ }^{1}$ Department of Pharmacology, P.D.U. Medical College, Rajkot, Gujarat, India. ${ }^{2}$ Department of Pharmacology, BJ Medical College, Ahmedabad, Gujarat, India. ${ }^{3}$ Department of Medicine, P.D.U. Medical College, Rajkot, Gujarat, India. Email-nirbharti_karelia@yahoo.co.in

Received: 20 June 2021, Revised and Accepted: 23 August 2021

\section{ABSTRACT}

Objective: The objective of this study is to assess adverse drug reaction (ADR) profile of the drugs prescribed to treat Coronavirus Disease (COVID-19) positive patients and to determine whether ADRs are associated with any comorbidities.

Methods: A cross-sectional study was done with Laboratory confirmed COVID-19 positive patients who experienced ADRs during their admission period at tertiary care center, Rajkot from April 2020 to March 2021. All the necessary information including ADRs information was obtained from patient's case record file and filled in suspected ADR reporting form. Suspected ADRs were assessed for demographic parameters and causality, preventability, and severity using World Health Organization (WHO) scale and Naranjo algorithm, modified Schumock and Thornton's criteria, and modified Hartwig's criteria, respectively.

Results: Out of the 100 patients there were 60 males. The mean age of the patients was $52.65 \pm 13.95$ year. Fourty-six patients had comorbidities. The most common type of ADR was GI disorders. Among the single suspected medication, most common drug was methylprednisolone and among the two drugs, azithromycin was common. According to the WHO and Naranjo scale, Probable ADRs were $70 \%$ and 36\%, respectively. The percentage for mild, moderate and severe ADRs were 44\%, 39\%, 17\%, respectively. Eighty-six percent ADRs were definitely preventable. Fifty-one patients were recovered from adverse reactions.

Conclusions: Seriousness of reactions is mainly associated with co-morbid conditions. This indicates that patients with comorbidity should be closely monitored to avoid harmful consequences. These ADRs monitoring and reporting program will help physicians to choose their therapy sensibly and decrease chances of mortality in this pandemic era.

Keywords: Coronavirus Disease-19, Adverse drug reactions, Health risk, Co-morbidity, Serious adverse drug reactions.

(C) 2021 The Authors. Published by Innovare Academic Sciences Pvt Ltd. This is an open access article under the CC BY license (http://creativecommons.org/ licenses/by/4.0/) DOI: http://dx.doi.org/10.22159/ajpcr.2021v14i10.42522. Journal homepage: https://innovareacademics.in/journals/index.php/ajpcr

\section{INTRODUCTION}

On December 31, 2019, a new respiratory viral disease identified in Wuhan, China. The disease was caused by a novel coronavirus named with severe acute respiratory syndrome coronavirus 2 (SARS-CoV-2). On March 12, 2020, the World Health Organization (WHO) declared a new pandemic all over the world because cases of Coronavirus Disease (COVID)-19 infection rapidly increase outside China [1,2]. According to Data taken from WHO, on February 21, 2021, confirmed cases were 110.7 million and over 2.4 million deaths occurred since the start of the pandemic [3]. The SARS-CoV-2 virus, which is an enveloped and single-stranded RNA virus belonging to the Coronaviridae family causes multiple organ system diseases in humans and animals. The signs and symptoms of COVID19 can varies from asymptomatic to severe symptoms. There is a difficulty to identify effective and safe treatments for COVID-19 disease. With the rapid spread of covid-19 disease in all over the world, the scientific authorities have developed treatment algorithms to treat COVID-19 infection. The treatment algorithms of COVID-19 are composed of medicinal drugs which have been utilized in preceding pandemics and the medications that have been thought potentially effective [4]. In response, National Institute of Health (NIH) provides guidelines to treat COVID-19. Antimicrobial drugs like hydroxychloroquine, azithromycin, remdesivir, ritonavir/ lopinavir, favipiravir used as antiviral drugs, immune-based drugs such as tocilizumab and corticosteroids and convalescent plasma with adjunctive therapy such as anticoagulants, Vitamin C, zinc were used [5]. These drugs are recommended as therapeutic drugs against COVID-19 infection, using those drugs in pandemic is experimental, and even compassionate use may pose health risks due to the potential to cause unfavorable adverse reactions [6,7]. Adverse drug reactions (ADRs) are a serious public health problem and contribute to increased morbidity and mortality in addition to prices for each sufferer and health systems. Prolong hospitalization of the patient, and increase difficulties to get bed in the hospital for new infected patients also associated with ADRs [7]. Considering the limited amount of safety information for the treatment of COVID-19, the study aims to evaluate the ADR profile in patients with the COVID-19 disease.

\section{MATERIALS AND METHODS}

\section{Study design and population}

This is a descriptive, cross-sectional, prospective as well as retrospective type of study conducted at COVID-19 hospital of tertiary care teaching hospital, Rajkot after ethically approved by the institutional ethics committee. The population consisted of COVID-19 confirmed hospitalized patients who presented with ADRs and were notified by ADR monitoring Center, Rajkot between April 2020 and March 2021.

\section{Data collection}

All data about ADR such as demographic profile, travel history, past mediation history and details about ADRs, suspected medications and relevant tests will be collected from COVID-19 hospital and was filled in special suspected ADR reporting form for drugs used in prophylaxis/treatment of COVID-19 provided by Indian Pharmacopeia Committee, Ghaziabad.

\section{Outcome variables}

Analysis of ADRs according to demographic profile, system organ classification (SOC), seriousness and outcome, related to travel history, 
COVID-19 test and comorbidity, Drug-drug interaction, etc. Reaction terminology was confirmed with Medical Dictionary for Regulatory Activities (MedDRA) in vigiflow. Drug-drug interaction checked with https://reference.medscape.com/drug-interactionchecker. Suspected ADRs were assessed for causality, preventability, and severity using the WHO causality assessment scale and Naranjo algorithm, modified Schumock and Thornton's criteria, and modified Hartwig's criteria, respectively [8-11].

\section{Statistical analysis}

The results are represented as Mean \pm SD and percentage and number using Microsoft Excel (office version 2019).

\section{RESULTS}

Total 100 ADR reports were collected. Out of them, there were 60 males and 40 females. The mean age of patients was $52.65 \pm 13.95$ years. As shown in Table 1 majority of ADRs noted between the age group of 50-70 years. Majority have reverse transcription-polymerase chain reaction (RT-PCR) test positive (78\%) as compared to rapid antigen test, no travel history (96\%) and majority have non-serious illness (51\%). About $54 \%$ of patients were without comorbidity and among comorbidity Diabetes Type- 2 and Hypertension were the most common. About 4\% ADR considered to be due to drug interaction and among them one interaction occurred with Enoxaparin and aspirin (Table 1)

According to SOC, ADRs related to Gastrointestinal disorders (41), metabolic disorders (29), bleeding disorders (16), cardiovascular disorders (06), General disorders (05), and psychiatric disorders (03) (Fig. 1).

As shown in (Table 2) majority of ADRs were suspected with single medication (69\%) as compared to two medications (30\%) and three medications (1\%). Among single drug therapy, most common drug was methylprednisolone and among two drugs azithromycin was common. Most common concomitant medication prescribed were paracetamol, chlorpheniramine, Vitamin $\mathrm{C}$, and multivitamins.

According to the WHO causality score, 70\% ADRs were probable and $30 \%$ were possible (Fig. 2). Considering Naranjo's scale $64 \%$ were possible and $36 \%$ were probable. Based on the modified Hartwig severity scale, most of the reactions were categorized as mild (44\%), moderate (39\%), and severe (17\%) in nature. According to Modified Schumock and Thornton's criteria, majority of reactions were definitely preventable (86\%) followed by probably preventable (14\%) (Table 3).

Regarding management of ADRs, among suspected single drug medication 26 reactions were subsided on withdrawal of drug, 39 without dose modification, and 4 on dose reduction. Among suspected two drugs, 3 reactions were subsided on withdrawal of both suspected drugs and 22 without dose modification and 5 reactions were subsided with one drug withdrawal while other suspected drug continued

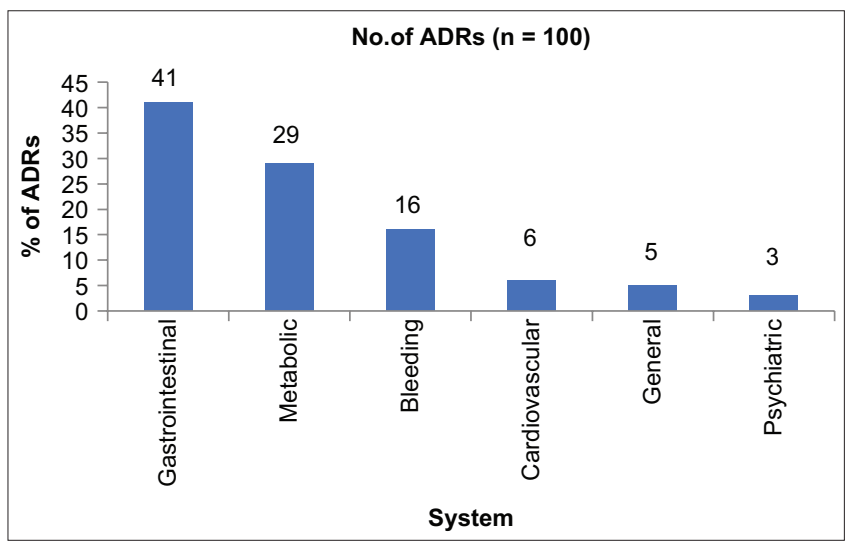

Fig. 1: Distribution of adverse drug reactions according to system organ classification
Table 1: Characteristics of the patients $(n=100)$

\begin{tabular}{ll}
\hline Parameters & $\begin{array}{l}\text { Number of ADRs } \\
\text { (\%) (n=100) }\end{array}$ \\
\hline Sex & $60(60 \%)$ \\
Male & $40(40 \%)$ \\
Female & \\
Age (years) & $10(10 \%)$ \\
$21-30$ & $15(15 \%)$ \\
$31-40$ & $16(16 \%)$ \\
$41-50$ & $25(25 \%)$ \\
$51-60$ & $28(28 \%)$ \\
$61-70$ & $6(6 \%)$ \\
$71-80$ & $78(78 \%)$ \\
Type of COVID-19 test & $22(22 \%)$ \\
RT-PCR & \\
Rapid antigen test & $04(4 \%)$ \\
Travel history & $96(96 \%)$ \\
Yes & \\
No & $46(46 \%)$ \\
Co-morbid conditions & $54(54 \%)$ \\
Yes & \\
No & $4(4 \%)$ \\
Drug interaction & $96(96 \%)$ \\
Yes & \\
No & \\
\hline &
\end{tabular}

Table 2: Distribution of ADRs according to suspected medication

\begin{tabular}{|c|c|c|}
\hline $\begin{array}{l}\text { Type of suspected } \\
\text { drug therapy }\end{array}$ & $\begin{array}{l}\text { No. of ADRs } \\
(\%)(n=100)\end{array}$ & Type of suspected drugs \\
\hline Single drug therapy & $69(69 \%)$ & $\begin{array}{l}\text { Methylprednisolone (27) } \\
\text { Azithromycin (23) } \\
\text { Enoxaparin (5) } \\
\text { Dexamethasone (3) } \\
\text { Ceftriaxone (3) } \\
\text { Hydroxychloroquine (2) } \\
\text { Heparin (2) } \\
\text { Favipiravir (1) } \\
\text { Piperacillin+Tazobactam (1) } \\
\text { Tocilizumab (1) } \\
\text { Remdesivir (1) }\end{array}$ \\
\hline Two drug therapy & $30(30 \%)$ & $\begin{array}{l}\text { Azithromycin (24) } \\
\text { Dexamethasone (21) } \\
\text { Hydroxychloroquine (5) } \\
\text { Enoxaparin (3) } \\
\text { Aspirin (2) } \\
\text { Remdesivir (2) } \\
\text { Metoprolol (1) } \\
\text { Methylprednisolone (1) } \\
\text { Dexamethasone (1) }\end{array}$ \\
\hline Three drug therapy & $1(1 \%)$ & $\begin{array}{l}\text { Azithromycin (1) } \\
\text { Heparin (1) } \\
\text { Ceftriaxone (1) }\end{array}$ \\
\hline
\end{tabular}

Table 3: Distribution of ADRs according to causality, severity, and preventability

\begin{tabular}{ll}
\hline Parameters & $\begin{array}{l}\text { No. of ADRs } \\
\text { (\%) (n=100) }\end{array}$ \\
\hline $\begin{array}{l}\text { Causality (Naranjo scale) } \\
\text { Possible }\end{array}$ & $64(64 \%)$ \\
$\quad$ Probable & $36(36 \%)$ \\
Severity (Modified Hartwig scale) & \\
$\quad$ Mild & $44(44 \%)$ \\
$\quad$ Moderate & $39(39 \%)$ \\
Severe & $17(17 \%)$ \\
Preventability (Modified Schumock and & \\
Thornton's criteria) & \\
$\quad$ Definitely preventable & \\
Probable preventable & $14(14 \%)$ \\
\hline
\end{tabular}




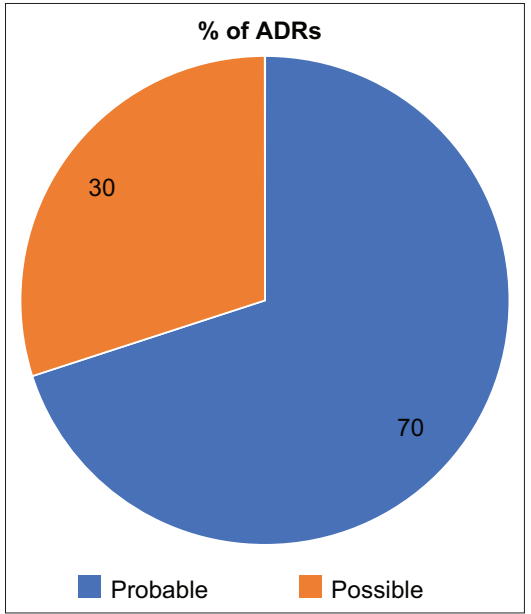

Fig. 2: Distribution of adverse drug reactions according to WHO causality scale

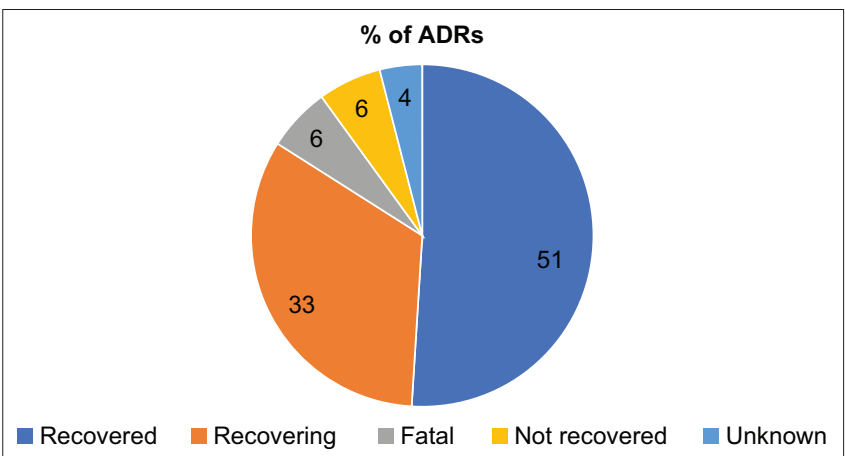

Fig. 3: Outcome of adverse drug reaction

Table 4: Distribution of ADRs according to type of management

\begin{tabular}{|c|c|c|}
\hline $\begin{array}{l}\text { Suspected } \\
\text { medication }\end{array}$ & Reaction abated on & $\begin{array}{l}\text { No. of ADRs } \\
(\%)(n=100)\end{array}$ \\
\hline \multirow[t]{4}{*}{ Single drug } & Without dose & $39(39 \%)$ \\
\hline & modification & \\
\hline & withdrawal & $26(26 \%)$ \\
\hline & Dose reduction & $4(4 \%)$ \\
\hline \multirow[t]{4}{*}{ Two drugs } & Without dose & $22(22 \%)$ \\
\hline & modification & \\
\hline & Without dose & $5(5 \%)$ \\
\hline & $\begin{array}{l}\text { modification+withdrawal } \\
\text { withdrawal }\end{array}$ & $3(3 \%)$ \\
\hline \multirow[t]{2}{*}{ Three drugs } & Without dose & $1(1 \%)$ \\
\hline & modification & \\
\hline
\end{tabular}

without dose modification. Among suspected three-drug medication 1 reaction subside without dose modification (Table 4).

Regarding outcome of ADR, recovered (51\%), recovering (33\%), not recovered (6\%), fatal (6\%), and unknown (4\%) (Fig. 3).

\section{DISCUSSION}

Since COVID-19 influences multi-organ systems, the infection and its treatment may also motive many adverse effects instead of aspect effects [4]. There is a determined want to pick out powerful treatment for coronavirus disorder. Most drugs recently used in this COVID-19 pandemic are repurposed antiviral and immunomodulatory drugs [12]. WHO in addition to the European Medicines Agency (EMA) have indicated the shortage of proof helping the efficacy and safety of any medicine in COVID-19 [13,14]. Hence, this study examined ADR occurred with experimental drugs used in COVID-19 and association between comorbidity and severity of ADRs.
The male predominance (60\%) in COVID-19 ADR reporting is steady with the consequences of an observe achieved through Zekarias et al. [15]. The mean age of patients for ADRs was $52.65 \pm 13.95$ years. Almost comparable end result visible with a study done by Sun et al. [16] our result confirmed that majority patients were tested positive by RTPCR and no travel history. Elderly populations are followed through comorbidity and polypharmacy leading to increases in unfavorable drug reactions (ADRs) [17]. Our result confirmed that majority ADRs occurred in patients whose age was between 50 and 70 years. Possible reasons could be the changes in pharmacokinetics with advancing age or Disease presentation-older age group patients were developing complications or leading to hospital admissions.

Drug-drug interactions occurring in the course of COVID-19 treatment and co-morbidities could lead to ADRs, which causes increasing the risk of hospitalization, prolonged time to recovery, or death on some cases [18]. In our observation, comorbidity has been found in $46 \%$ of cases of ADR and drug-drug interaction was observed in $4 \%$ of cases.

According to SOC most common ADRs associated with GIT disorders (41\%), which is inconsistent with the results of a study performed by Crescioli et al. [19]. Among them, Diarrhea was the most common symptom and suspected medication was antibiotics that is established truth that diarrhea is common adverse effect of antibiotics [20]. Other study reported that ADRs cited with two or more suspected drug therapy [19]. In comparison to this, our result confirmed that ADRs cited with single suspected medication (69\%) were higher than two (30\%) and three (1\%) suspected drug therapy. Methylprednisolone is more common with single suspected and azithromycin is more common with two suspected drug therapy. Steroids are the principle motive of drug-induced hyperglycemia. They not only exacerbate hyperglycemia in patients with known diabetes mellitus but also cause DM in patients without documented hyperglycemia before the initiation of glucocorticoids therapy $[21,22]$. Also in our study metabolic disorders noted the second most common ADRs and among them, hyperglycemia was the most common symptom.

Considering causality assessment our end result showed that $70 \%$ ADRs were probable and $30 \%$ were possible as per the WHO causality assessment scale which changed into contrary from the questionary primarily based totally Naranjo's algorithm, where 36\% ADRs were probable and $64 \%$ were possible and additionally contrary to observe performed through Melo et al. where 19.8\% ADRs were probable and $67.4 \%$ were possible. According to Hartwig's severity scale, mild ADRs have been described as those which does not by itself require prolongation of hospitalization and could be managed by simple measures, moderate were those ADRs which needed prolongation of hospital stay of the patient for treatment of the same and severe were life-threatening ADRs [23].

According to our observations, most of the unfavorable drug reactions were categorized as mild (44\%) and moderate (39\%). Only $17 \%$ of ADRs have been categorized as severe ADRs. According to Preventability (Modified Schumock and Thornton's) criteria majority have been actually definitely preventable ADRs (86\%). Considering management, we found that the majority of ADRs abated on without dose modification whether suspected medication was single or two drugs. Finally, concerning final results of ADRs majority were recovered (51\%) and recovering phase (33\%). Similar result observed in study performed by Melo et al. wherein 62.3\% recovered and 21.7\% in recovering phase.

\section{CONCLUSION}

Comorbid and elderly patients should be closely monitored for ADRs to avoid harmful consequences in this COVID-19 pandemic situation. The pharmacovigilance program of India (PvPI) will work as important tool to help physicians to choose their therapy sensibly and decrease chances of mortality in this pandemic era. 


\section{AUTHOR'S CONTRIBUTIONS}

Dr. Ridhdhi H. was involved in data collection, data organization, data interpretation, data analysis, preparation, reviewing, and editing of the manuscript. Dr. Bharti K. was involved in data interpretation, data analysis, preparation, and reviewing of article. Dr. Anil and Dr. Aarti were involved in reviewing and guiding this article.

\section{CONFLICT OF INTEREST}

None.

\section{AUTHOR'S FUNDING}

None.

\section{REFERENCES}

1. Epidemiology Working Group for NCIP Epidemic Response, Chinese Center for Disease Control and Prevention. The epidemiological characteristics of an outbreak of 2019 novel Coronavirus diseases (COVID-19) in China. Zhonghua Liu Xing Bing Xue Za Zhi 2020;41:145-51.

2. Li X, Wang W, Zhao X, Zai J, Zhao Q, Li Y, et al. Transmission dynamics and evolutionary history of 2019-nCoV. J Med Virol 2020;92:501-11.

3. Coronavirus Disease (COVID-19) Situation Reports; 2021. Available from: https://www.who.int/emergencies/diseases/novelcoronavirus-2019/situation-reports. [Last accessed on 2021 Jul 15].

4. Izci F, Kulacaoglu F. Drug interactions between COVID-19 and psychiatric medications: A mini review. J Neurobehav Sci 2020;7:103- 8 .

5. Information on COVID-19 Treatment, Prevention and Research; 2021. [Last accessed on $2021 \mathrm{Jul} 15]$. Available from: https://www. covid19treatmentguidelines.nih.gov.

6. Kalil AC. Treating COVID-19-off-label drug use, compassionate use, and randomized clinical trials during pandemics. JAMA 2020;323:1897- 8

7. Melo JR, Duarte EC, Moraes MV, Fleck K, Silva AS, Arrais PSD. Adverse drug reactions in patients with COVID-19 in Brazil: Analysis of spontaneous notifications of the Brazilian pharmacovigilance system. Cad Saude Publica 2021;37:e00245820.

8. Zaki SA. Adverse drug reaction and causality assessment scales. Lung India 2011;28:152-3.

9. Naranjo CA, Busto U, Sellers EM, Sandor P, Ruiz I, Roberts EA, et al. A method for estimating the probability of adverse drug reactions. Clin
Pharmacol Ther 1981;30:239-45.

10. Schumock GT, Thornton JP. Focusing on the preventability of adverse drug reactions. Hosp Pharm 1992;27:538.

11. Hartwig SC, Siegel J, Schneider PJ. Preventability and severity assessment in reporting adverse drug reactions. Am J Hosp Pharm 1992;49:2229-32.

12. Thomas ZM, Taegtmeyer AL, Jamiolkowski D, Enders FB, Hofmeier KS, Hartmann K, et al. Emerging treatments in COVID-19: Adverse drug reactions including drug hypersensitivities. J Allergy Clin Immunol 2020;146:786-9.

13. WHO Clinical Management of Severe Acute Respiratory Infection (SARI) When COVID-19 Disease is Suspected. Interim Guidance; 2020. [Last accessed on 2020 Mar 30]. Available from: https://www. apps.who.int/iris/handle/10665/331446

14. Global Regulators Stress Need for Robust Evidence on COVID-19 Treatments; 2020. [Last accessed on 2020 Apr 09]. Available from: https://www.ema.europa.eu/en/documents/press-release/globalregulators-stress-need-robust-evidence-covid-19-treatments_en.pdf.

15. Zekarias A, Watson S, Vidlin SH, Grundmark B. Sex differences in reported adverse drug reactions to COVID-19 drugs in a global database of individual case safety reports. Drug Saf 2020;43:1309-14.

16. Sun J, Deng X, Chen X, Huang J, Huang S, Li Y, et al. Incidence of adverse drug reactions in COVID-19 patients in China: An active monitoring study by hospital pharmacovigilance system. Clin Pharmacol Ther 2020;108:791-7.

17. Wood SD, Yoon J, Doo JE, Park Y, Lee Y, Lee SH, et al. Common causes and characteristics of adverse drug reactions in older adults: A retrospective study. BMC Pharmacol Toxicol 2020;21:87.

18. Awortwe C, Cascorbi I. Meta-analysis on outcome-worsening comorbidities of COVID-19 and related potential drug-drug interactions. Pharmacol Res 2020;161:105250.

19. Crescioli G, Brilli V, Lanzi C, Burgalassi A, Leri A, Bonaiuti R, et al. Adverse drug reactions in SARS-CoV-2 hospitalized patients: A caseseries with a focus on drug-drug interactions. Intern Emerg Med 2021;16:697-710.

20. McFarland LV. Diarrhoea associated with antibiotic use. BMJ 2007:335:54-5.

21. Trence DL. Management of patients on chronic glucocorticoid therapy: An endocrine perspective. Prim Care 2003;30:593-605.

22. Hirsch IB, Paauw DS. Diabetes management in special situations. Endocrinol Metab Clin North Am 1997;26:631-45.

23. Belhekar MN, Tondare SB, Pandit PR, Bhave KA, Patel TC. A prospective study on causality, severity and preventability assessment of adverse drug reactions in a tertiary care hospital in India. Int J Basic Clin Pharmacol 2019;8:104-10. 